\title{
The Association between Dietary Inflammatory Index (DII) and Cancer Risk in Korea: A Prospective Cohort Study within the KoGES-HEXA Study
}

\author{
Injeong Ryu ${ }^{1, \dagger}{ }^{+}$, Minji Kwon ${ }^{2, \dagger}$, Cheongmin Sohn ${ }^{3}$, Nitin Shivappa ${ }^{4,5,6}$, James R. Hébert ${ }^{4,5,6} \mathbb{D}^{\text {, }}$ \\ Woori $\mathrm{Na}^{3}{ }^{-1}$ and Mi Kyung Kim ${ }^{2, *(D)}$ \\ 1 Department of Food and Nutrition, Yonsei University, Seoul 03722, Korea; dlswjd5158@gmail.com \\ 2 Division of Cancer Epidemiology and Management, National Cancer Center, Goyang-si, \\ Gyeonggi-do 10408, Korea; 74433@ncc.re.kr \\ 3 Department of Food and Nutrition, Wonkwang University, Iksan-si, Jeollabuk-do 54538, Korea; \\ ccha@wku.ac.kr (C.S.); nawoori6@gmail.com (W.N.) \\ 4 Cancer Prevention and Control Program, University of South Carolina, Columbia, SC 29208, USA; \\ SHIVAPPA@mailbox.sc.edu (N.S.); JHEBERT@mailbox.sc.edu (J.R.H.) \\ 5 Department of Epidemiology and Biostatistics, Arnold School of Public Health, University of South Carolina, \\ Columbia, SC 29208, USA \\ 6 Connecting Health Innovations LLC, Columbia, SC 29201, USA \\ * Correspondence: alrud@ncc.re.kr; Tel.: +82-31-920-2202; Fax: +82-31-920-2006 \\ + Equally contributed to this work.
}

Received: 20 September 2019; Accepted: 21 October 2019; Published: 23 October 2019

\begin{abstract}
Several epidemiological studies have shown that there are consistently positive associations between dietary inflammatory index $\left(\mathrm{DII}{ }^{\circledR}\right)$ scores and cancer incidence in Western populations. However, few DII-cancer studies have been conducted in East Asian populations. In a large cohort representative of the general Korean population, we investigated whether the DII is associated with overall cancer risk. A total of 163,660 participants (56,781 males and 106,879 females) had evaluable data for analyses. This follow-up study was carried out over the course of 7.9 years. DII scores were calculated based on Semi-Quantitative Food-Frequency Questionnaire (SQ-FFQ) data for 106 food items. Cancers were self-reported based on notification by the participants' medical doctors. Multivariable Cox proportional hazard regression was used to estimate hazard ratios (HRs) with 95\% confidence intervals (CIs). After the follow-up, 1643 incident cases of cancer (520 males and 1123 females) had developed. In a fully adjusted model, women in the highest DII quintile showed a $44 \%$ increased risk of getting cancer $\left(\mathrm{HR}_{\mathrm{Q} 5 \mathrm{vs} Q 1}=1.44 ; 95 \% \mathrm{CI}=1.14-1.82 ; p\right.$-trend $\left.=0.0006\right)$, while men showed no apparent association $\left(\mathrm{HR}_{\mathrm{Q} 5 \mathrm{vs} 1}=0.80 ; 95 \% \mathrm{CI}=0.58-1.10\right)$. These results indicate that in Korean women, a more pro-inflammatory diet is associated with a higher risk of incident cancer.
\end{abstract}

Keywords: cancer; inflammatory mediator; diet; antioxidant; epidemiology; dietary inflammatory index

\section{Introduction}

Cancer is the generic term for a group of diseases that arises from abnormal cell growth, which can lead to metastasis in a multistage process. According to the World Health Organization (WHO), cancer is the second leading cause of death worldwide, responsible for 9.6 million deaths in 2018, notably causing $70 \%$ of deaths in developing countries [1]. In South Korea, cancer is the first leading cause of death: The number of deaths caused by cancer in 2018 was $86,281,28.9 \%$ of the total 
incidence of death [2]. Development of cancer is influenced by genetic, environmental, and lifestyle factors. The main risk factors are tobacco, alcohol, unhealthy diet, and physical inactivity, while other factors include radiation, stress, environmental pollutants, and genetic defects [1,3]. Cancer onset inflicts physical and mental pain on patients and their families and puts them under financial strain. Furthermore, from the view of society, it leads to economic losses due to decreased human resources and productivity, while increasing national healthcare expenditures [4]. Hence, it is important to map out strategies for cancer prevention in order to reduce financial burden and suffering on individuals and for the nation as a whole.

Inflammation is part of the innate immune reaction that responds to tissue damage induced by pathogens, damaged cells, or irritants [5-7]. When inflammation occurs, activated macrophages and lymphocytes secrete inflammatory mediators, amplifying immune response [8]. There is robust evidence that several inflammatory mediators such as tumor necrosis factor (TNF- $\alpha$ ), interleukin (IL)-6, IL-10, transforming growth factor $\beta$ (TGF- $\beta$ ), and high-sensitivity c-reactive protein (hs-CRP) are critical components of oxidative DNA damage, triggering malignant tumor progression $[6,9,10]$. Meanwhile, previous studies have verified that diet can modulate levels of inflammatory mediators [11-13] and cancer development $[14,15]$. The degree to which inflammation occurs as a result of diet can be determined via the dietary inflammatory index $\left(\mathrm{DII}{ }^{\circledR}\right)$, a score that measures the inflammatory potential of food items based on dietary patterns within any study population [16].

Several studies have shown that higher DII score is associated with elevated levels of inflammatory mediators, which include TNF- $\alpha$, IL- 6 and hs-CRP, indicating strong link between DII and cancer [8,17-21]. Many epidemiological studies have also contributed towards growing evidence for associations between DII and specific cancers [22-30]. On the other hand, several other such studies have shown only ambiguous associations between DII and cancers [31,32]. Notwithstanding these conflicting results, a majority of studies, including meta-analyses, have concluded that there are consistent positive associations between DII and cancer incidence across cancer types, populations, and study designs [33-44]. However, most of the relevant studies have been conducted with Western populations and have targeted specific cancers. As far as we know, there have been few pertinent studies thus far on East Asian populations [45-50]. In the present large cohort study representative of the Korean population, which entails 7.9 years of follow-up, we tested the hypothesis that a higher DII score is associated with higher risk of cancer.

\section{Materials and Methods}

\subsection{Data Collection and Subject Recruitment}

The data used in this study were collected from the cohort of the KOREA GENOME and Epidemiology Study (KoGES), including the KoGES_Ansan and Ansung study, the KoGES_cardiovascular disease association study (CAVAS), and the KoGES_health examinee study (HEXA). In order to gather participants' genetic, environmental, and lifestyle information affecting cancer expression, candidate subjects based on the Korean population, both males and females aged $\geq 40$ years, had been recruited from the National Health Examinee Registry. Data representative of that cohort from the KoGES-HEXA study were used in the present study to examine the association between DII and cancer expression. Detailed information on the KoGES can be found elsewhere [51].

The participants were asked to respond to the multiple-choice survey voluntarily. The 173,343 participants (59,291 males and 114,052 females) were enrolled from 38 health examination centers and hospitals located in eight regions in Korea between 2004 and 2013 and were asked to attend a follow-up study conducted over the course of the 7.9 years (2007-2016). Among this original population, 4274 people who had insufficient energy intake (males $<500 \mathrm{kcal}$ or $\geq 6000 \mathrm{kcal}$; females $<500 \mathrm{kcal}$ or $\geq 4000 \mathrm{kcal}$ ) and 5409 people who had cancer already at the baseline or missing data were excluded. Thus, the valid subjects numbered 163,660 (56,781 males and 106,879 females). After the 7.9-year follow-up study, the total cancer incidence was 1643 (520 cases in males and 1123 cases in 
females), and identification of cancer expression was self-reported after diagnosis by a medical doctor (Figure 1). All of the subjects provided written consent prior to this study, which was approved by the Institutional Review Board of the National Cancer Center in Korea and followed all of the relevant guidelines and regulations (IRB No. NCC2018-0164).

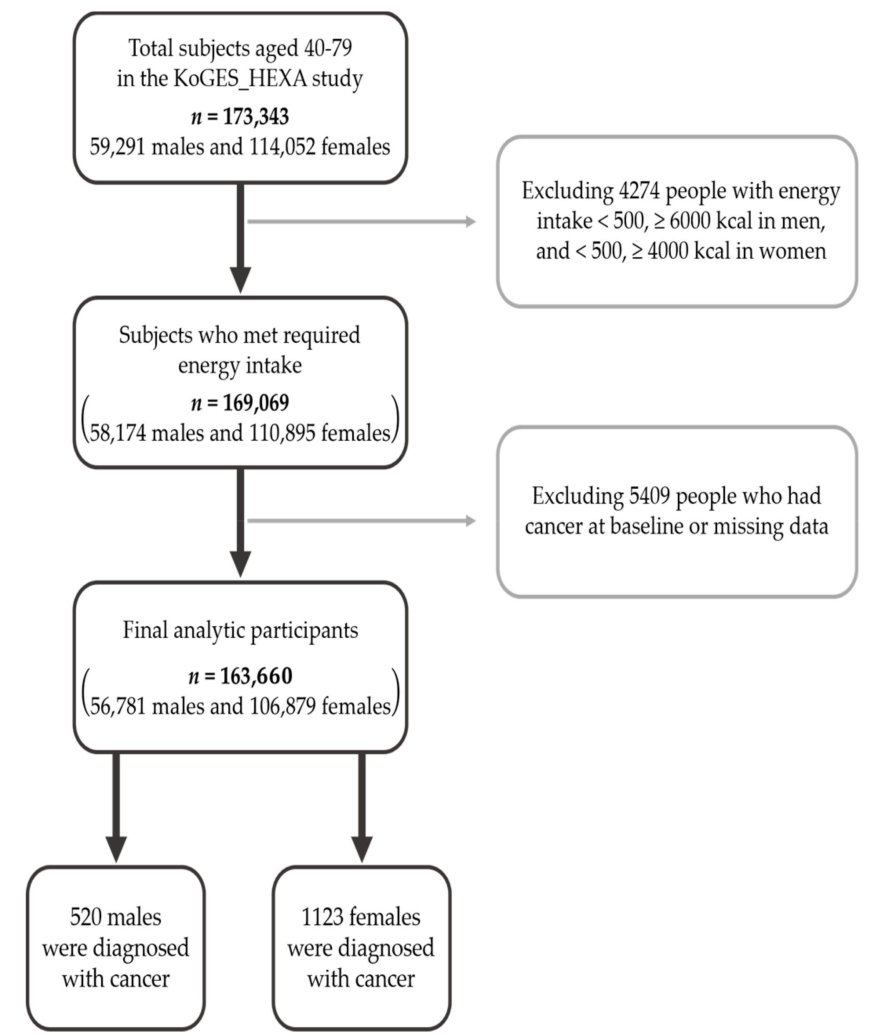

Figure 1. Flow chart of analytical samples in KoGES_HEXA Study.

\subsection{Calculation}

Dietary food intake was measured with a Semi-Quantitative Food Frequency Questionnaire (SQ-FFQ). The validity of the SQ-FFQ was proven in a previous study [52]. Dietary intake was measured once, at the beginning of the study, regarding the past year of intake. The study participants reported the daily intake amounts (g), average portion sizes and serving frequencies of 106 foods. The portion size was divided into three levels: half a serving, a standard serving, and three-half servings, and frequencies were categorized into nine levels, from "almost never" to "more than three times a day". Total calories and nutrient intakes were calculated with a Korean standard food composition table [53].

For the updated version of DII, 1943 articles were reviewed and scored. Forty-five food parameters, including foods, nutrients, and other bioactive compounds, were identified according to their capacity for changing the levels of specific inflammatory markers (i.e., hs-CRP, IL-1 $\beta$, IL-4, IL-6, IL-10, and TNF- $\alpha$ ). Regionally representative data sets based on diet surveys from 11 countries were collectively used as comparative standards for each of the 45 parameters.

To calculate the DII scores, the intake scores of the above-noted data sets were applied. A paper on DII methodology provides more detailed information [16]. To summarize, Z scores were generated by subtracting a standard mean, as derived from the world data sets for each food parameter, from the actual scores and dividing it by its standard deviation. These $\mathrm{Z}$ scores were converted into percentile ranks in order to minimize the effects of outliers or right-skewing. These values were doubled, and 1 was subtracted, to make the distribution symmetric relative to 0 . The resulting values were then 
multiplied by the corresponding inflammatory score for each food parameter, and all were summed to obtain the overall DII score.

In this study, the following 37 food parameters were adopted to calculate DII: anthocyanidins, green and black tea, $\mathrm{Zn}, \mathrm{Mg}$, Fe, Se, vitamins $\left(\mathrm{A}, \mathrm{B}_{6}, \mathrm{~B}_{12}, \mathrm{C}, \mathrm{D}, \mathrm{E}\right)$, thiamin, MUFA, PUFA, niacin, garlic, onion, folic acid, fiber, protein, total fat, saturated fatty acids, trans fat, n-3 fatty acid, n- 6 fatty acid, carbohydrate, cholesterol, caffeine, carotene, riboflavin, isoflavone, flavanone, flavonol, flavones, flavan-3-ol, and calories. From among these 37 food parameters, the pro-inflammatory parameters include vitamin $B_{12}$, total fat, protein, saturated fatty acids, trans fat, n- 6 fatty acid, carbohydrate, cholesterol and calories, and anti-inflammatory parameters include anthocyanidins, green and black tea, $\mathrm{Zn}, \mathrm{Mg}, \mathrm{Fe}$, Se, vitamins (A, B 6 , C, D, E), thiamin, MUFA, PUFA, niacin, garlic, onion, folic acid, fiber, n-3 fatty acid, caffeine, carotene, riboflavin, isoflavones, flavanone, flavonol, flavones, and flavan-3-ol.

\subsection{Covariates}

In the present study, 12 covariates, representing a questionnaire on personal and family medical history, physical and mental health, lifestyle, and FFQ, were selected as potential moderator variables. These included age, BMI, and energy for continuous variables and gender, marital status, educational level, income, smoking, drinking, physical activity, menopausal status, and family history of cancer for categorical variables. Gender was sorted by biological sex: male and female. Marital status was divided into two categories: married and single or divorced or widowed. Educational level was divided into three levels: $<$ Middle school and Middle school to College and $\geq$ College. Monthly income was recorded based on 10,000 won as the unit and was divided into four levels: $<100,100 \sim 200,200 \sim 300$, and $\geq 300$. With regard to smoking, subjects who had been smoking more than 400 cigarettes at the time of the survey were classified as "current", who had smoked more than 400 cigarettes but quit smoking as "past", and who had not smoked more than 400 cigarettes as "never". As for drinking, those who had been drinking at the time of the survey were classified as "current", those who had been drinking but quit as "past", and those who had never drunk as "never". Menopausal status was sorted into post-menopause and pre- or peri-menopause, and it was determined by whether participants experienced menstrual cycles within the past one year. Regular physical activity was defined as exercising regularly enough to sweat. Those who fulfilled the criteria were considered as doing "regular" physical activity, while those who did not fulfill the criteria were considered as doing "irregular" physical activity. Family history of cancer was classified into "Yes" and "No".

\subsection{Statistical Analysis}

The study subjects were classified into five groups (quintiles) based on their DII scores. DII quintiles were divided based on a no-incidence group. Continuous variables were presented as means with standard deviation, and categorical variables were presented as frequency numbers with percentages. To calculate the $p$ values for trends, the Jonckheere-Terpstra test and the Mantel-Haenszel Chi-square test were applied to the continuous variables and categorical variables, respectively. The Cox proportional hazard model was used to find any association between the DII quintiles and cancer incidence. The fully adjusted model was adjusted for age and energy as continuous variables and sex (for the total), marital status, education, smoking, drinking, physical activity, and family history of cancer as categorical variables. The HRs were calculated with $95 \%$ confidence intervals. To confirm the assumption of proportional risk, the models including time-dependent covariates were evaluated. To determine the effects of the DII components on cancer risk, the contents of the food parameters were adjusted for energy and divided into quintiles, after which the multivariable proportional hazard model was re-applied. $p$ values for trends were calculated for both continuous and categorical DII and DII components. Additionally, the $p$ interaction for gender and categorical DII in the fully adjusted Cox model was calculated. $p<0.05$ was deemed statistically significant. All of the statistical tests were performed using SAS program version 9.4 (SAS Institute, Cary, NC, USA). 


\section{Results}

The demographic characteristics of 163,660 subjects according to DII quintiles are presented in Table 1. The range of the highest DII quintile is 2.1973 to 7.1056 (SD =0.82) and the lowest DII quintile is -9.1296 to -0.9589 ( $\mathrm{SD}=1.08$ ). As DII increased, the mean age of the subjects increased, while the mean BMI and mean energy intake have tended to decrease. The proportion of females decreased in higher-DII quintiles. The proportion of participants who were married decreased as DII increased. The income level and educational level also decreased as DII increased. To put it concretely, in higher (i.e., more pro-inflammatory) DII quintiles, there were more people earning less than 1,000,000 won a month but fewer people earning more than 3,000,000 won a month. There also were more people who had not finished middle school but fewer people who had more than a bachelor's degree. The proportion of "current" smokers showed a tendency to increase and that of "never" smokers to decrease, as DII increased, while the proportions of "current" drinkers decreased and "never" drinkers increased. The percentage of women of post-menopausal status was higher as DII increased. By contrast, the percentage of people who exercised regularly was lower as DII increased. Family history of cancer did not show any remarkable tendency across DII quintiles. To sum up, as the DII increased, mean age, proportion of males, proportion of smokers, and proportion of post-menopausal status increased, while mean BMI, mean energy intake, proportion of married status, educational level, income level, proportion of drinker, and proportion of people who exercise regularly decreased. All of the $p$ values were less than 0.0001 .

After carrying out 7.9-years follow-up on 163,660 subjects, 1643 cases of cancer (520 males and 1123 females) were detected. The most common cancer in women was breast cancer ( 239 cases), and the most common cancer in men was gastric cancer (137 cases). The rate of overall cancer development was $14 \%$ higher for women $(1.05 \%)$ than for men $(0.92 \%)$. To identify whether DII is associated with cancer risk, a proportional hazard model was applied, and nine possible confounding variables listed in Table 1 were used to generate a fully adjusted hazard model.

The results stratified by gender are presented in Table 2 . As can be seen, a statistically significant result was observed only among females. In the fully adjusted hazard model, women with the highest DII range $(=\mathrm{Q} 5)$ had a $44 \%$-higher risk of getting cancer relative to the reference $(=\mathrm{Q} 1)$ $(\mathrm{HR}=1.44 ; 95 \% \mathrm{CI}=1.14-1.82)$. The $p$ trend also showed strong evidence in its significance (categorical $\mathrm{DII}=0.0022$; continuous DII $=0.0006$ ). We also observed a near significant association for overall analyses. ( $\mathrm{HR}=1.20 ; 95 \% \mathrm{CI}=0.99-1.45)$. However, there were no statistically significant associations between DII and cancer incidence among males $(\mathrm{HR}=0.80 ; 95 \% \mathrm{CI}=0.58-1.10)$. The $p$ interaction between gender (male/female) and categorical DII in the fully adjusted Cox model was 0.0594.

In order to examine which of the 37 food parameters applied to DII calculation facilitate or reduce the risk of cancer, the proportional hazard model was applied again.

As shown in Table 3, statistically significant results for DII components were observed in women. Among the 37 food parameters, seven (isoflavone, flavanone, flavonol, flavan-3-ol, green and black tea, riboflavin, and iron) were found to reduce cancer incidence. Compared with the reference (=Q1), the hazard ratio (HR) of the highest DII components' contents (=Q5) showed that isoflavone reduces the incidence of cancer in women by $22 \%(\mathrm{HR}=0.78 ; 95 \% \mathrm{Cl}=0.64-0.95)$, flavanone by $19 \%(\mathrm{HR}=0.81$; $95 \% \mathrm{CI}=0.67-0.98)$, flavonol by $34 \%(\mathrm{HR}=0.66 ; 95 \% \mathrm{CI}=0.54-0.82)$, flavan-3-ol by $32 \%(\mathrm{HR}=0.68$; $95 \% \mathrm{CI}=0.55-0.84)$, green and black tea by $35 \%(\mathrm{HR}=0.65 ; 95 \% \mathrm{CI}=0.54-0.77)$, riboflavin by $19 \%$ $(\mathrm{HR}=0.81 ; 95 \% \mathrm{CI}=0.67-0.99)$, and iron by $20 \%(\mathrm{HR}=0.80 ; 95 \% \mathrm{CI}=0.66-0.97)$. However, in terms of $p$ trends, six components (isoflavone, flavonol, flavan-3-ol, green and black tea, riboflavin, and iron) showed strong evidence of their significance, while flavanone showed only weak evidence (categorical component $=0.3148$; continuous component $=0.1618$ ) . 
Table 1. Selected variables at baseline according to Dietary Inflammatory Index (DII), KoGES 2004-2013.

\begin{tabular}{|c|c|c|c|c|c|c|}
\hline \multirow{2}{*}{$\begin{array}{c}\text { Variables }^{b} \\
(\text { Mean (SD) or } n(\%))\end{array}$} & \multicolumn{5}{|c|}{ Quintiles of Dietary Inflammatory Index (DII) ${ }^{a}$} & \multirow{2}{*}{$p$ Value $^{\mathrm{c}}$} \\
\hline & Q1 & Q2 & Q3 & Q4 & Q5 & \\
\hline & $n=32,757$ & $n=32,721$ & $n=32,757$ & $n=32,733$ & $n=32692$ & \\
\hline & $-9.1296--0.9589$ & $-0.9588-0.4180$ & $0.4180-1.3036$ & $1.3036-2.1973$ & $2.1973-7.1056$ & \\
\hline Age (years) & $52.2(8.0)$ & $52.3(8.2)$ & $52.7(8.2)$ & $53.3(8.5)$ & $54.6(8.7)$ & $<0.0001$ \\
\hline BMI $\left(\mathrm{kg} / \mathrm{m}^{2}\right)$ & $24.1(2.9)$ & $24.0(2.9)$ & $24.0(2.9)$ & $23.8(2.9)$ & $23.8(3.0)$ & $<0.0001$ \\
\hline Energy (kcal/day) & $2266.0(580)$ & $1901.5(425)$ & $1669.8(373)$ & $1496.3(388)$ & $1407.7(366)$ & $<0.0001$ \\
\hline \multicolumn{7}{|c|}{ Gender } \\
\hline Male & $11,002(33.6)$ & $11,419(34.9)$ & $11,513(35.2)$ & $11,207(34.2)$ & $11,640(35.6)$ & \multirow{2}{*}{$<0.0001$} \\
\hline Female & $21,755(66.4)$ & $21,302(65.1)$ & $21,244(64.9)$ & $21,526(65.8)$ & $21,052(64.4)$ & \\
\hline \multicolumn{7}{|c|}{ Marital status } \\
\hline Married & $29,345(90.2)$ & $29,218(89.9)$ & $28,955(88.8)$ & $28,279(86.9)$ & $27,474(84.5)$ & \multirow[b]{2}{*}{$<0.0001$} \\
\hline Single/Divorced/Widowed & $3198(9.8)$ & $3298(10.1)$ & $3638(11.2)$ & $4274(13.1)$ & $5029(15.5)$ & \\
\hline \multicolumn{7}{|c|}{ Education level } \\
\hline$<$ Middle school & $3915(12.1)$ & 4404 (13.7) & $5241(16.2)$ & 6359 (19.7) & $8631(26.8)$ & \multirow{3}{*}{$<0.0001$} \\
\hline Middle school College & $19,132(59.2)$ & $18,885(58.5)$ & $18,684(57.8)$ & $18,518(57.4)$ & $17,795(55.2)$ & \\
\hline$\geq$ College & $9271(28.7)$ & $8983(27.8)$ & $8423(26.0)$ & $7406(22.9)$ & $5792(18.0)$ & \\
\hline \multicolumn{7}{|c|}{ Monthly income $(10,000$} \\
\hline$<100$ & $2178(8.1)$ & $2343(8.5)$ & $2851(10.4)$ & $3670(13.3)$ & $4982(17.8)$ & \multirow{4}{*}{$<0.0001$} \\
\hline $100 \sim 200$ & $4843(18.1)$ & $5167(18.8)$ & $5472(19.9)$ & $5954(21.6)$ & $6811(24.4)$ & \\
\hline $200 \sim 300$ & $6175(23.0)$ & $6580(23.9)$ & $6298(22.9)$ & $6110(22.2)$ & $5946(21.3)$ & \\
\hline$\geq 300$ & $13,609(50.8)$ & $13,426(48.8)$ & $12,909(46.9)$ & $11,803(42.9)$ & $10,232(36.6)$ & \\
\hline \multicolumn{7}{|c|}{ Smoking } \\
\hline Never & $24,091(73.9)$ & $23,694(72.7)$ & $23,761(72.8)$ & 23,904 (73.3) & $22,921(70.3)$ & \multirow{3}{*}{$<0.0001$} \\
\hline Past & 4567 (14.0) & 4957 (15.2) & $4953(15.2)$ & 4745 (14.5) & $4758(14.6)$ & \\
\hline Current & 3940 (12.1) & 3941 (12.1) & 3940 (12.1) & 3977 (12.2) & 4919 (15.1) & \\
\hline
\end{tabular}


Table 1. Cont.

\begin{tabular}{|c|c|c|c|c|c|c|}
\hline \multirow{2}{*}{$\begin{array}{c}\text { Variables }^{b} \\
(\text { Mean }(\mathrm{SD}) \text { or } n(\%))\end{array}$} & \multicolumn{5}{|c|}{ Quintiles of Dietary Inflammatory Index (DII) ${ }^{a}$} & \multirow{2}{*}{$p$ Value } \\
\hline & Q1 & Q2 & Q3 & Q4 & Q5 & \\
\hline \multicolumn{7}{|c|}{ Drinking } \\
\hline Never & $16,051(49.2)$ & $15,902(48.8)$ & $16,257(49.8)$ & $16,727(51.3)$ & $17,203(52.8)$ & \\
\hline Past & $1250(3.8)$ & $1157(3.6)$ & $1131(3.5)$ & $1303(4.0)$ & $1288(4.0)$ & $<0.0001$ \\
\hline Current & $15,319(47.0)$ & $15,541(47.7)$ & $15,284(46.8)$ & $14,606(44.8)$ & $14,114(43.3)$ & \\
\hline \multicolumn{7}{|c|}{ Physical activity $\mathrm{d}$} \\
\hline Irregular & $11,002(33.6)$ & $11,419(34.9)$ & $11,513(35.2)$ & $11,207(34.2)$ & $11,640(35.6)$ & \\
\hline Regular & $21,755(66.4)$ & $21,302(65.1)$ & $21,244(64.9)$ & $21,526(65.8)$ & $21,052(64.4)$ & $<0.0001$ \\
\hline \multicolumn{7}{|c|}{ Menopausal status } \\
\hline Post-menopause & $11,311(56.3)$ & $11,396(56.5)$ & $11,712(58.0)$ & $12,493(61.0)$ & $13,546(66.2)$ & \\
\hline Pre-menopause & $8765(43.7)$ & $8787(43.5)$ & $8487(42.0)$ & $7994(39.0)$ & $6928(33.8)$ & $<0.0001$ \\
\hline \multicolumn{7}{|c|}{ Family history of cancer } \\
\hline Yes & $8778(26.8)$ & $9157(28.0)$ & $8980(27.4)$ & $8882(27.1)$ & $8609(26.3)$ & \multirow{2}{*}{$<0.0001$} \\
\hline No & $23,979(73.2)$ & $23,564(72.0)$ & $23,777(72.6)$ & $23,851(72.9)$ & $24,083(73.7)$ & \\
\hline
\end{tabular}

${ }^{\mathrm{a}}$. Quintile 1 indicates least inflammatory diet (lowest DII), and Quintile 5 indicates most inflammatory diet (highest DII). ${ }^{\mathrm{b}}$. The data of continuous variables are presented as mean with standard deviation, and the data of categorical variables are presented as frequency number with percentage. ${ }^{c}$. $p$ values for trends were calculated using the Jonckheere-Terpstra test for continuous variables and the Mantel-Haenszel Chi-square test for categorical variables. ${ }^{d}$. Regularity of physical activity was defined according to whether or not subjects participated regularly in any sports to the point of sweating. 
Table 2. Cox proportional Hazard Ratios (HRs) with 95\% Confidence Intervals (CIs) for incidence of cancer expression according to Dietary Inflammatory Index (DII), KoGES 2004-2013.

\begin{tabular}{|c|c|c|c|c|c|c|c|}
\hline & \multicolumn{5}{|c|}{ Quintiles of Dietary Inflammatory Index (DII) ${ }^{a}$} & \multirow{2}{*}{$p$ Value $^{b}$} & \multirow{2}{*}{$p$ Value $^{\mathrm{c}}$} \\
\hline & Q1 & Q2 & Q3 & Q4 & Q5 & & \\
\hline \multicolumn{8}{|c|}{ All subjects } \\
\hline Person-years & 255,579 & 245,501 & 243,536 & 240,475 & 230,054 & & \\
\hline Incidence $(n)$ & 353 & 317 & 354 & 330 & 289 & & \\
\hline Unadjusted & 1.00 & $0.94(0.81-1.10)$ & $1.05(0.91-1.22)$ & $1.04(0.89-1.20)$ & $1.14(0.98-1.34)$ & 0.05 & 0.11 \\
\hline Fully adjusted ${ }^{d}$ & 1.00 & $0.99(0.84-1.16)$ & $1.10(0.93-1.29)$ & $1.11(0.93-1.32)$ & $1.20(0.99-1.45)$ & 0.03 & 0.0432 \\
\hline \multicolumn{8}{|c|}{ Male } \\
\hline Person-years & 83,738 & 84,350 & 85,104 & 82,214 & 82,916 & & \\
\hline Incidence $(\mathrm{N})$ & 118 & 91 & 108 & 102 & 101 & & \\
\hline Unadjusted & 1.00 & $0.73(0.56-0.96)$ & $0.82(0.63-1.06)$ & $0.84(0.64-1.09)$ & $0.98(0.75-1.27)$ & 0.89 & 0.67 \\
\hline Fully adjusted ${ }^{\mathrm{d}}$ & 1.00 & $0.69(0.52-0.92)$ & $0.74(0.55-1.00)$ & $0.75(0.55-1.03)$ & $0.80(0.58-1.10)$ & 0.42 & 0.16 \\
\hline \multicolumn{8}{|c|}{ Female } \\
\hline Person-years & 171,841 & 161,151 & 158,432 & 158,261 & 147,138 & & \\
\hline Incidence (N) & 235 & 226 & 246 & 228 & 188 & & \\
\hline Unadjusted & 1.00 & $1.06(0.88-1.27)$ & $1.18(0.99-1.41)$ & $1.14(0.9-1.37)$ & $1.23(1.0-1.49)$ & $<0.0001$ & $<0.0001$ \\
\hline Fully adjusted ${ }^{d}$ & 1.00 & $1.16(0.96-1.41)$ & $1.31(1.07-1.61)$ & $1.32(1.06-1.64)$ & $1.44(1.14-1.82)$ & 0.002 & 0.0006 \\
\hline
\end{tabular}


Table 3. Multivariable Cox proportional Hazard Ratios (HRs) with $95 \%$ Confidence Intervals (CIs) for components effecting reduced DII level in women.

\begin{tabular}{|c|c|c|c|c|c|c|c|}
\hline \multirow{2}{*}{ Components } & \multicolumn{5}{|c|}{ Quintiles of DII Components ${ }^{a}$} & \multirow{2}{*}{$p$ Value $^{\mathrm{b}}$} & \multirow{2}{*}{$p$ Value } \\
\hline & Q1 & Q2 & Q3 & Q4 & Q5 & & \\
\hline \multicolumn{8}{|c|}{ Isoflavone } \\
\hline Incidence $(n)$ & 197 & 224 & 252 & 223 & 227 & & \\
\hline $\mathrm{HRs}^{\mathrm{d}}$ & 1.00 & $0.99(0.81-1.20)$ & $1.06(0.88-1.28)$ & $0.87(0.72-1.06)$ & $0.78(0.64-0.95)$ & 0.003 & 0.005 \\
\hline \multicolumn{8}{|c|}{ Flavanone } \\
\hline Incidence $(n)$ & 193 & 167 & 199 & 267 & 297 & & \\
\hline $\mathrm{HRs}^{\mathrm{d}}$ & 1.00 & $0.78(0.63-0.97)$ & $0.85(0.69-1.04)$ & $0.97(0.80-1.17)$ & $0.81(0.67-0.98)$ & 0.31 & 0.16 \\
\hline \multicolumn{8}{|c|}{ Flavonol } \\
\hline Incidence $(n)$ & 167 & 237 & 251 & 254 & 214 & & \\
\hline $\mathrm{HRs}^{\mathrm{d}}$ & 1.00 & $1.05(0.86-1.29)$ & $0.89(0.73-1.09)$ & $0.79(0.65-0.97)$ & $0.66(0.54-0.82)$ & $<0.0001$ & 0.002 \\
\hline \multicolumn{8}{|c|}{ Flavan-3-ol } \\
\hline Incidence $(n)$ & 165 & 260 & 243 & 244 & 211 & & \\
\hline HRs $^{d}$ & 1.00 & $1.06(0.86-1.29)$ & $0.93(0.76-1.14)$ & $0.81(0.66-0.99)$ & $0.68(0.55-0.84)$ & $<0.0001$ & 0.002 \\
\hline \multicolumn{8}{|c|}{ Green and Black tea } \\
\hline Incidence $(n)$ & 412 & 12 & 242 & 246 & 211 & & \\
\hline HRs $^{d}$ & 1.00 & $0.59(0.32-1.09)$ & $0.89(0.76-1.05)$ & $0.78(0.66-0.91)$ & $0.65(0.54-0.77)$ & $<0.0001$ & 0.002 \\
\hline \multicolumn{8}{|c|}{ Riboflavin } \\
\hline Incidence $(n)$ & 200 & 220 & 225 & 246 & 232 & & \\
\hline HRs $^{d}$ & 1.00 & $1.05(0.86-1.28)$ & $1.06(0.87-1.29)$ & $1.04(0.86-1.26)$ & $0.81(0.67-0.99)$ & 0.03 & 0.05 \\
\hline \multicolumn{8}{|c|}{$\mathrm{Fe}$} \\
\hline Incidence (N) & 203 & 203 & 225 & 251 & 241 & & \\
\hline $\mathrm{HRs}^{\mathrm{d}}$ & 1.00 & $0.94(0.77-1.14)$ & $0.97(0.80-1.18)$ & $0.99(0.82-1.20)$ & $0.80(0.66-0.97)$ & 0.05 & 0.03 \\
\hline
\end{tabular}




\section{Discussion}

In this large Korean cohort study, we investigated the association between inflammatory potential of diet, referred to as DII, and the risk of cancer development. We determined that a pro-inflammatory diet (the highest DII scores) increased the risk of cancer in women. After a 7.9-year follow-up, the result obtained for women showed a $44 \%$ higher risk of getting cancer in the most pro-inflammatory DII quintile compared with the lowest DII quintile (representing the most anti-inflammatory diet) after multivariable adjustment. Moreover, a similarly positive association was found between energy-adjusted DII (E-DII) and risk of cancer among women $\left(\mathrm{HR}_{\mathrm{Q} 5 \mathrm{vs} Q 1}=1.27(1.04-1.56)\right)$. However, no significant result was observed for men. These results are partially consistent with our hypothesis that higher DII is associated with higher risk of cancer in the Korean population.

There have been many studies examining the association between DII and cancer incidence. Most case-control studies and cohort studies have shown positive associations between DII and cancer incidence [23-30]. In addition, there have now been over 10 meta-analyses that have all shown consistently positive results [33-44]. On the other hand, some studies have reported statistically non-significant associations between DII and cancer incidence. In a cohort-study involving ten screening centers across the United States, no statistically significant association was observed between DII and pancreatic cancer $\left(\mathrm{HR}_{\mathrm{Q} 5 \mathrm{vs} Q 1}=1.31(0.83-2.08)\right)$ [31]. Moreover, in a case-control study in Mexico, likewise, there was no significant association between prostate cancer risk and E-DII $\left(\mathrm{OR}_{\mathrm{T} 3 \mathrm{vsT1}}=1.18(0.85-1.63)\right)$ [32].

However, most of the aforementioned studies targeted specific cancers that appear usually in only one gender, such as breast cancer, cervical cancer, and prostate cancer, or analyzed without stratification of gender. Among the investigations on the association between DII and cancer incidence, only a few have shown gender difference in their results. In these studies, most of them found significant results for men but not for women. According to a prospective cohort study that used data from the Västerbotten Intervention Programme, researchers observed a statistically significant result, which was that an anti-inflammatory diet helped to reduce the risk of lung cancer (men; $\mathrm{HR}_{\mathrm{T} 3 \mathrm{vsT} 1}=0.81$ (0.66-0.99), women; $\mathrm{HR}_{\mathrm{T} 3 \mathrm{vsT} 1}=0.89(0.74-1.08)$ ) and gastric cancer (men; $\mathrm{HR}_{\mathrm{T} 3 \mathrm{vsT} 1}=0.73$ (0.53-0.99), women; $\left.\mathrm{HR}_{\mathrm{T} 3 \mathrm{vs} T 1}=0.97(0.70-1.34)\right)$ only in men [54]. Meanwhile, a Japanese study on the association between DII and hs-CRP (which is used as an index of cancer screening) suggested that DII is correlated with elevated hs-CRP level in Japanese men but not in women (men; $\mathrm{OR}_{\mathrm{CRP}>0.3 \mathrm{mg} / \mathrm{dLvs} \leq 0.3 \mathrm{mg} / \mathrm{dL}}=1.17$ (1.02-1.35), women; $\left.\mathrm{OR}_{\mathrm{CRP}>0.3 \mathrm{mg} / \mathrm{dLvs} \leq 0.3 \mathrm{mg} / \mathrm{dL}}=0.99(0.79-1.24)\right)$ [55]. In a case-control study from Iran, a significant association between DII and colorectal cancer was found, once again, only in men (men; $\mathrm{OR}_{\mathrm{DII}>-0.23 \mathrm{vs} \leq-0.23}=33.95$ (3.72-309.44), women; $\mathrm{OR}_{\mathrm{DII}>-0.23 \mathrm{vs} \leq-0.23}=0.60(0.22-1.61)$ ) [56].

In our study, however, there was a positive association between DII and cancer incidence not for men but only for women. To the best of our knowledge, there have been only two study results coinciding with the current ones. Case-control studies on Korean populations showed a positive association between DII and gastric cancer (men; $\mathrm{OR}_{\mathrm{T} 3 \mathrm{vsT} 1}=1.31(0.84-2.05)$, women; $\mathrm{OR}_{\mathrm{T} 3 \mathrm{vsT} 1}=2.98$ (1.68-5.30) [57] and proximal colon cancer (men; $\mathrm{OR}_{\mathrm{T} 3 \mathrm{vsT} 1}=1.51(0.89-2.57)$, women; $\mathrm{OR}_{\mathrm{T} 3 \mathrm{vsT} 1}=2.23$ (1.02-4.89)) only in women [58], suggesting that the associations between DII and cancer incidence are stronger in women than in men in this population.

Although studies that support our results are not sufficiently numerous, previous studies investigating gender differences in immune response provide possible explanations. Due to differences of hormonal status and rare genes on the $X$ chromosome, inflammation-related genes of females can be over expressed, resulting in poorer prognoses for females when they suffer from chronic inflammatory diseases such as rheumatoid arthritis, inflammatory bowel disease, and other autoimmune diseases [59-61]. Additionally, in the process of inflammation, hs-CRP levels, the erythrocyte sedimentation rate, and neutrophil counts, which are biomarkers used to identify cancer incidence, are higher for females than for males [61-63]. These results substantiate the contention that chronic inflammatory disease is predominant in women. However, some researchers have posited conflicting mechanisms with other chronic inflammatory disease in the case of cancer, due to differences 
in physiology, regulation of gene expression and epigenetic mechanisms, and due also to the fact that, as for most cancers, males generally have higher susceptibility than females [64]. As noted above, evidence in the form of epidemiological results is also accumulating [54-56]. The obscure effect of the DII in men in this study may be related to the simple fact that men, in general, have more pro-inflammatory diets than women. In this study, men had a higher mean DII score $(0.684 ; \mathrm{SD}=1.96)$ than did women $(0.610 ; \mathrm{SD}=1.93)$. Moreover, there are statistically significant differences in DII scores between men and women (Wilcoxon rank-sum test, $p<0.0001$ ). It is possible that the DII distribution for men was so skewed to the pro-inflammatory diet (higher DII) that it could not fully reflect the inflammatory potential of diet. Since not only there are no tangible reasons for gender differences in associations between DII and cancer incidence but also the results of our study contradict those of previous studies, further investigations with larger sample sizes and sufficient statistical power are needed in order to determine whether there are any gender differences in the associations between DII and cancer incidence.

The present study also confirmed that among the 37 DII components, seven (isoflavone, flavanone, flavonol, flavan-3-ol, riboflavin, green and black tea, and iron), known as antioxidants, help reduce cancer risk in women. Several mechanisms have been proposed to explain the effects of antioxidants in alleviating inflammation. In the inflammatory response, an oxidative environment is formed, since leukocytes and mast cells release reactive oxygen species (ROS), while inflammatory cells generate inflammatory mediators in the damage regions [65-67]. Under the healthy condition, the human body can balance between ROS and antioxidant enzymes; however, if the body's equilibrium is disturbed, oxidative stress, which might trigger carcinogenesis in turn, can be incurred [68,69]. Antioxidant supplements help to avoid oxidative stress by balancing ROS. Thereby, they prevent vital cellular components such as DNA, proteins, and membrane lipids from being damaged, which normally would lead to cell death $[67,70]$. In particular, flavonoids, known as typical antioxidants, exert a protective role in tumor development by inhibiting cancer cell growth and proliferation with concomitant induction of apoptosis in the absence of cytotoxicity [71]. Moreover, riboflavin (vitamin B2), as a component of the glutathione redox cycle, has antioxidant properties [72], and iron also protects cells from the effects of free radicals, specifically in its role as a supplier of effective reducing agents, ferric ions $\left(\mathrm{Fe}^{3+}\right)[73]$. In line with the above mechanisms, we found that riboflavin, iron, three subtypes of flavonoids (i.e., isoflavone, flavonol and flavan-3-ol) and green and black tea, which is rich in polyphenols, including flavonoids and phenolic acid, have strong effects in reducing cancer incidence. However, flavanone shows weak evidence of any significance, and flavone and anthocyanidin, two other subtypes of flavonoids, along with onion, which contain much quercetin, a type of flavonol, show non-significant results. Such results, moreover, have been observed only in women.

Another interesting finding is that the proportion of "current" drinkers was higher in the lower DII quintiles. This is consistent with a previous study on the association between alcohol consumption and concentrations of inflammatory biomarkers. Daily alcohol intake showed an apparent U-shaped association with hs-CRP and fibrinogen. In other words, moderate alcohol consumption has negative correlations with elevated inflammatory biomarkers, appearing to have an anti-inflammatory effect $[74,75]$. However, given that "moderate" alcohol consumption may vary by individual, and given also that there are heterogeneous epidemiological results indicating that even moderate alcohol consumption increases cancer incidence [76], further epidemiological studies involving subjects of diverse demographic characteristics are needed in order to determine what properly represents a "moderate" amount of alcohol. Also required are studies on the associations among inflammation, cancer incidence, and moderate alcohol consumption.

In addition, we saw caloric intake decreased in higher-DII quintiles, which is contrary to the common notion that calories are pro-inflammatory components. Underlying our observations in light of all of the many studies which have been conducted to date using the DII are two countervailing effects. The first is a positive correlation between energy intake and nutrient intake, resulting from a tendency to eat more of everything as one increases energy intake. The other is "healthy eater" effect 
(e.g., health-conscious people prefer choosing nutrient-dense and energy-sparse foods) [77]. In this study, we anticipated the first effect was more dominant than the "healthy eater" effect. The subjects with lower DII followed a more anti-inflammatory diet such as fruits and vegetables, which are rich in vital micronutrients and bio-active compounds as well as macronutrients. Since there is a positive correlation between energy intake and nutrient intake, consuming more fruits and vegetables contributed to greater caloric intake. Hence, in lower DII quintile, we saw higher values of not only pro-inflammatory components like energy and macronutrients but also vital micronutrients and other bioactive compounds considered to be anti-inflammatory components.

There are several limitations to the present study. First, selection bias might have been incurred. The subjects had been recruited from 38 health examination centers and hospitals located in urban areas of Korea, and only those willing to participate were enrolled; consequently, the number of women who consented to the study was higher than that of men; they might not be entirely representative of the Korean population. This type of screening bias occurs in many prospective cohort studies [78]. Second, cancer diagnosis was self-reported, and as such, errors in the numbers of cancer incidences might have been incurred. Third, among the 45 food parameters of DII, we used data on only 37, excluding the remaining eight. Although this can be considered to be a study limitation, it was perhaps not a major factor having a significant impact on the outcome, because those eight components are not frequently consumed. Moreover, whereas we identified the effects of the overall inflammatory mediators on cancer incidence through DII, we did not observe the effects of individual inflammatory markers such as hs-CRP, IL-1 $\beta$, IL-4, IL-6, IL-10 or (TNF)- $\alpha$. The lack of information on associations between DII and specific cancers might be another limitation, since we targeted all cancers. In spite of the above limitations, our study has strengths. It is a prospective cohort study with a large sample size and a long-term follow-up. Hence, relative to case-control studies, it reduces the chance of recall bias and provides reliable results. Above all, the present study is important in terms of its provision of accumulated evidence of a positive association between DII and cancer risk. We expect that the present study will contribute to the enhancement of public health by emphasizing the importance of a healthy diet and also by raising public awareness of the dangers of a pro-inflammatory diet.

\section{Conclusions}

Higher DII scores were associated with higher risk of cancer incidence in Korean women. More epidemiological studies, particularly those on the association between DII and cancer for various world populations, are needed.

Author Contributions: Study design and conduct, M.K.K.; integrity of data analysis: N.S., M.K., W.N., and C.S.; statistical analysis: M.K.K., M.K., and I.R.; data interpretation and drafting of manuscript: I.R., M.K., W.N., C.S., N.S., J.R.H., and M.K.K.; primary responsibility for final version: M.K.K.

Funding: The present study was financially supported by a grant (1910181) from the National Cancer Center, Korea.

Acknowledgments: Data utilized in this study were obtained from the Korean Genome and Epidemiology Study (KoGES; 4851-302), National Research Institute of Health, Centers for Disease Control and Prevention, Ministry for Health and Welfare, Republic of Korea.

Conflicts of Interest: No author declares a conflict. James R. Hébert owns a controlling interest in Connecting Health Innovations LLC (CHI), a company that is planning to license the right to his invention of the dietary inflammatory index (DII) from the University of South Carolina in order to develop computer and smart phone applications for patient counseling and dietary intervention in clinical settings. Nitin Shivappa is an employee of $\mathrm{CHI}$. The subject matter of this paper will not have any direct bearing on that work, nor has that activity exerted any influence on this project.

\section{References}

1. World Health Organization. Cancer. Available online: https://www.who.int/cancer/en/ (accessed on 18 July 2019).

2. World Health Organization. Korea, Republic of Source: Globocan 2018. Available online: http://gco.iarc.fr/ today/data/factsheets/populations/410-korea-republic-of-fact-sheets.pdf (accessed on 18 July 2019). 
3. Anand, P.; Kunnumakkara, A.B.; Sundaram, C.; Harikumar, K.B.; Tharakan, S.T.; Lai, O.S.; Sung, B.; Aggarwal, B.B. Cancer is a Preventable Disease that Requires Major Lifestyle Changes. Pharm. Res. 2008, 25, 2200. [CrossRef]

4. Choi, B.; Um, T.R.; Lee, K. Factors related to cancer screening behaviors. Epidemiol. Health 2018, 40, e2018011. [CrossRef] [PubMed]

5. Ferrero-Miliani, L.; Nielsen, O.H.; Andersen, P.S.; Girardin, S.E. Chronic inflammation: Importance of NOD2 and NALP3 in interleukin-1 $\beta$ generation. Clin. Exp. Immunol. 2007, 147, 227-235. [CrossRef] [PubMed]

6. Landskron, G.; De la Fuente, M.; Thuwajit, P.; Thuwajit, C.; Hermoso, M.A. Chronic inflammation and cytokines in the tumor microenvironment. J. Immunol. Res. 2014, 2014, 149185. [CrossRef]

7. National Cancer Institute. Chronic Inflammation. Available online: https://www.cancer.gov/about-cancer/ causes-prevention/risk/chronic-inflammation (accessed on 18 July 2019).

8. Schottenfeld, D.; Beebe-Dimmer, J. Chronic Inflammation: A common and important factor in the pathogenesis of neoplasia. CA Cancer J. Clin. 2006, 56, 69-83. [CrossRef]

9. Colotta, F.; Allavena, P.; Sica, A.; Garlanda, C.; Mantovani, A. Cancer-related inflammation, the seventh hallmark of cancer: Links to genetic instability. Carcinogenesis 2009, 30, 1073-1081. [CrossRef]

10. Il'yasova, D.; Colbert, L.H.; Harris, T.B.; Newman, A.B.; Bauer, D.C.; Satterfield, S.; Kritchevsky, S.B. Circulating Levels of Inflammatory Markers and Cancer Risk in the Health Aging and Body Composition Cohort. Cancer Epidemiol. Biomark. Prev. 2005, 14, 2413-2418. [CrossRef]

11. Galland, L. Diet and Inflammation. Nutr. Clin. Pract. 2010, 25, 634-640. [CrossRef]

12. De Mello, V.D.F.; Schwab, U.; Kolehmainen, M.; Koenig, W.; Siloaho, M.; Poutanen, K.; Mykkänen, H.; Uusitupa, M. A diet high in fatty fish, bilberries and wholegrain products improves markers of endothelial function and inflammation in individuals with impaired glucose metabolism in a randomised controlled trial: The Sysdimet study. Diabetologia 2011, 54, 2755-2767. [CrossRef]

13. Luciano, M.; Mõttus, R.; Starr, J.M.; McNeill, G.; Jia, X.; Craig, L.C.A.; Deary, I.J. Depressive symptoms and diet: Their effects on prospective inflammation levels in the elderly. Brain Behav. Immun. 2012, 26, 717-720. [CrossRef]

14. Donaldson, M.S. Nutrition and cancer: A review of the evidence for an anti-cancer diet. Nutr. J. $2004,3,19$. [CrossRef] [PubMed]

15. Koriech, O.M. Diet and cancer. J. Fam. Community Med. 1994, 1, 2-11.

16. Shivappa, N.; Steck, S.E.; Hurley, T.G.; Hussey, J.R.; Hébert, J.R. Designing and developing a literature-derived, population-based dietary inflammatory index. Public Health Nutr. 2014, 17, 1689-1696. [CrossRef] [PubMed]

17. Shivappa, N.; Hébert, J.R.; Marcos, A.; Diaz, L.; Gomez, S.; Nova, E.; Michels, N.; Arouca, A.; González-Gil, E.; Frederic, G.; et al. Association between dietary inflammatory index and inflammatory markers in the HELENA study. Mol. Nutr. Food Res. 2017, 61, 1600707. [CrossRef]

18. Na, W.; Kim, M.; Sohn, C. Dietary inflammatory index and its relationship with high-sensitivity C-reactive protein in Korean: Data from the health examinee cohort. J. Clin. Biochem. Nutr. 2018, 62, 83-88. [CrossRef]

19. Tabung, F.K.; Smith-Warner, S.A.; Chavarro, J.E.; Fung, T.T.; Hu, F.B.; Willett, W.C.; Giovannucci, E.L. An empirical dietary inflammatory pattern score enhances prediction of circulating inflammatory biomarkers in adults. J. Nutr. 2017, 147, 1567. [CrossRef]

20. Shivappa, N.; Hébert, J.R.; Rietzschel, E.R.; De Buyzere, M.L.; Langlois, M.; Debruyne, E.; Marcos, A.; Huybrechts, I. Associations between dietary inflammatory index and inflammatory markers in the Asklepios Study. Br. J. Nutr. 2015, 113, 665-671. [CrossRef]

21. Ren, Z.; Zhao, A.; Wang, Y.; Meng, L.; Szeto, I.M.; Li, T.; Gong, H.; Tian, Z.; Zhang, Y.; Wang, P. Association between Dietary Inflammatory Index, C-Reactive Protein and Metabolic Syndrome: A Cross-Sectional Study. Nutrients 2018, 10, 831. [CrossRef]

22. Peres, L.C.; Bandera, E.V.; Qin, B.; Guertin, K.A.; Shivappa, N.; Hébert, J.R.; Abbott, S.E.; Alberg, A.J.; Barnholtz-Sloan, J.; Bondy, M.; et al. Dietary inflammatory index and risk of epithelial ovarian cancer in African American women. Int. J. Cancer 2017, 140, 535-543. [CrossRef]

23. Zucchetto, A.; Gini, A.; Shivappa, N.; Hébert, J.R.; Stocco, C.; Dal Maso, L.; Birri, S.; Serraino, D.; Polesel, J. Dietary inflammatory index and prostate cancer survival. Int. J. Cancer 2016, 139, 2398-2404. [CrossRef]

24. Shivappa, N.; Hébert, J.R.; Zucchetto, A.; Montella, M.; Serraino, D.; La Vecchia, C.; Rossi, M. Dietary inflammatory index and endometrial cancer risk in an Italian case-control study. Br. J. Nutr. 2016, 115, 138-146. [CrossRef] [PubMed] 
25. Shivappa, N.; Prizment, A.E.; Blair, C.K.; Jacobs, D.R., Jr.; Steck, S.E.; Hébert, J.R. Dietary inflammatory index and risk of colorectal cancer in the Iowa Women's Health Study. Cancer Epidemiol. Biomark. Prev. 2014, 23, 2383-2392. [CrossRef] [PubMed]

26. Vahid, F.; Shivappa, N.; Hatami, M.; Sadeghi, M.; Ameri, F.; Jamshidi Naeini, Y.; Hébert, J.R.; Davoodi, S.H. Association between Dietary Inflammatory Index (DII) and Risk of Breast Cancer: A Case-Control Study. Asian Pac. J. Cancer Prev. 2018, 19, 1215. [PubMed]

27. Vahid, F.; Shivappa, N.; Faghfoori, Z.; Khodabakhshi, A.; Zayeri, F.; Hébert, J.R.; Davoodi, S.H. Validation of a Dietary Inflammatory Index (DII) and Association with Risk of Gastric Cancer: A Case-Control Study. Asian Pac. J. Cancer Prev. 2018, 19, 1471.

28. Shivappa, N.; Jackson, M.D.; Bennett, F.; Hébert, J.R. Increased Dietary Inflammatory Index (DII) Is Associated with Increased Risk of Prostate Cancer in Jamaican Men. Nutr. Cancer 2015, 67, 941-948. [CrossRef]

29. Shivappa, N.; Hébert, J.R.; Paddock, L.E.; Rodriguez-Rodriguez, L.; Olson, S.H.; Bandera, E.V. Dietary inflammatory index and ovarian cancer risk in a New Jersey case-control study. Nutrition 2018, 46, 78-82. [CrossRef]

30. Shivappa, N.; Hébert, J.R.; Rosato, V.; Rossi, M.; Montella, M.; Serraino, D.; La Vecchia, C. Dietary inflammatory index and ovarian cancer risk in a large Italian case-control study. Cancer Causes. Control 2016, 27, 897-906. [CrossRef]

31. Zheng, J.; Merchant, A.T.; Wirth, M.D.; Zhang, J.; Antwi, S.O.; Shoaibi, A.; Shivappa, N.; Stolzenberg-Solomon, R.Z.; Hébert, J.R.; Steck, S.E. Inflammatory potential of diet and risk of pancreatic cancer in the Prostate, Lung, Colorectal and Ovarian (PLCO) Cancer Screening Trial: DII and pancreatic cancer risk in the PLCO study. Int. J. Cancer 2018, 142, 2461-2470. [CrossRef]

32. Vázquez-Salas, R.A.; Shivappa, N.; Galván-Portillo, M.; López-Carrillo, L.; Hébert, J.R.; Torres-Sánchez, L. Dietary inflammatory index and prostate cancer risk in a case-control study in Mexico. Br. J. Nutr. 2016, 116, 1945-1953. [CrossRef]

33. Fowler, M.E.; Akinyemiju, T.F. Meta-analysis of the association between dietary inflammatory index (DII) and cancer outcomes. Int. J. Cancer 2017, 141, 2215-2227. [CrossRef]

34. Fan, Y.; Jin, X.; Man, C.; Gao, Z.; Wang, X. Meta-analysis of the association between the inflammatory potential of diet and colorectal cancer risk. Oncotarget 2017, 8, 59592-59600. [CrossRef] [PubMed]

35. Shivappa, N.; Godos, J.; Hébert, J.R.; Wirth, M.D.; Piuri, G.; Speciani, A.F.; Grosso, G. Dietary Inflammatory Index and Colorectal Cancer Risk-A Meta-Analysis. Nutrients 2017, 9, 1043. [CrossRef] [PubMed]

36. Jayedi, A.; Emadi, A.; Shab-Bidar, S. Dietary Inflammatory Index and Site-Specific Cancer Risk: A Systematic Review and Dose-Response Meta-Analysis. Adv. Nutr. 2018, 9, 388-403. [CrossRef] [PubMed]

37. Li, D.; Hao, X.; Li, J.; Wu, Z.; Chen, S.; Lin, J.; Li, X.; Dong, Y.; Na, Z.; Zhang, Y.; et al. Dose-response relation between dietary inflammatory index and human cancer risk: Evidence from 44 epidemiologic studies involving 1,082,092 participants. Am. J. Clin. Nutr. 2018, 107, 371-388. [CrossRef] [PubMed]

38. Lu, D.L.; Ren, Z.J.; Zhang, Q.; Ren, P.W.; Yang, B.; Liu, L.R.; Dong, Q. Meta-analysis of the association between the inflammatory potential of diet and urologic cancer risk. PLoS ONE 2018, 13, e0204845. [CrossRef] [PubMed]

39. Mohseni, R.; Abbasi, S.; Mohseni, F.; Rahimi, F.; Alizadeh, S. Association between Dietary Inflammatory Index and the Risk of Prostate Cancer: A Meta-Analysis. Nutr. Cancer 2018, 71, 359-366. [CrossRef]

40. Moradi, S.; Issah, A.; Mohammadi, H.; Mirzaei, K. Associations between dietary inflammatory index and incidence of breast and prostate cancer: A systematic review and meta-analysis. Nutrition 2018, 55, 168-178. [CrossRef]

41. Namazi, N.; Larijani, B.; Azadbakht, L. Association between the dietary inflammatory index and the incidence of cancer: A systematic review and meta-analysis of prospective studies. Public Health 2018, 164, 148-156. [CrossRef]

42. Wang, L.; Liu, C.; Zhou, C.; Zhuang, J.; Tang, S.; Yu, J.; Tian, J.; Feng, F.; Liu, L.; Zhang, T.; et al. Meta-analysis of the association between the dietary inflammatory index (DII) and breast cancer risk. Eur. J. Clin. Nutr. 2018, 25, 25. [CrossRef]

43. Zahedi, H.; Djalalinia, S.; Sadeghi, O.; Asayesh, H.; Noorozi, M.; Gorabi, A.M.; Mohammadi, R.; Qorbani, M. Dietary Inflammatory Potential Score and Risk of Breast Cancer: A systematic review and meta-analysis. Clin. Breast Cancer 2018, 18, e561-e570. [CrossRef] 
44. Liu, Z.Y.; Gao, X.P.; Zhu, S.; Liu, Y.H.; Wang, L.J.; Jing, C.X.; Zeng, F.F. Dietary inflammatory index and risk of gynecological cancers: A systematic review and meta-analysis of observational studies. J. Gynecol. Oncol. 2019, 30, e23. [CrossRef] [PubMed]

45. Tang, L.; Shivappa, N.; Hébert, J.R.; Lee, A.H.; Xu, F.; Binns, C.W. Dietary inflammatory index and risk of oesophageal cancer in Xinjiang Uyghur Autonomous Region, China. Br. J. Nutr. 2018, 119, 1068-1075. [CrossRef] [PubMed]

46. Hoang, D.V.; Shivappa, N.; Pham, N.M.; Hébert, J.R.; Binns, C.W.; Lee, A.H. Dietary inflammatory index is associated with increased risk for prostate cancer among Vietnamese men. Nutrition 2019, 62, 140-145. [CrossRef] [PubMed]

47. Huang, W.; Mo, X.; Ye, Y.; Shivappa, N.; Lin, F.; Huang, J.; Hébert, J.R.; Yan, B.; Zhang, C. A higher Dietary Inflammatory Index score is associated with a higher risk of breast cancer among Chinese women: A case-control study. Br. J. Nutr. 2017, 117, 1358-1367. [CrossRef]

48. Shivappa, N.; Wang, R.; Hébert, J.R.; Jin, A.; Koh, W.; Yuan, J.M. Association between inflammatory potential of diet and risk of lung cancer among smokers in a prospective study in Singapore. Eur. J. Nutr. 2018. [CrossRef]

49. Wang, X.; Fang, A.; Chen, P.; Liao, G.; Zhang, Y.; Shivappa, N.; Hébert, J.R.; Chen, Y.; Zhu, H. High dietary inflammatory index scores are associated with an elevated risk of hepatocellular carcinoma in a case-control study. Food. Funct. 2018, 9, 5832-5842. [CrossRef]

50. Sreeja, S.R.; Lee, H.Y.; Kwon, M.; Shivappa, N.; Hébert, J.R.; Kim, M.K. Dietary Inflammatory Index and Its Relationship with Cervical Carcinogenesis Risk in Korean Women: A Case-Control Study. Cancers 2019, 11, e1108.

51. Kim, Y.; Han, B.G. Cohort Profile: The Korean Genome and Epidemiology Study (KoGES) Consortium. Int. J. Epidemiol. 2017, 46, 1350. [CrossRef]

52. Ahn, Y.; Kwon, E.; Shim, J.E.; Park, M.K.; Joo, Y.; Kimm, K.; Park, C.; Kim, D.H. Validation and reproducibility of food frequency questionnaire for Korean genome epidemiologic study. Eur. J. Clin. Nutr. 2007, 61, 1435-1441. [CrossRef]

53. National Institute of Agricultural Sciences. Korean Food Composition Table, 9th ed.; Rural Development Administration, National Institute of Agricultural Sciences: Jeonju, Korea; Available online: http://koreanfood. rda.go.kr/eng/fctFoodSrchEng/engMain (accessed on 31 July 2019).

54. Bodén, S.; Myte, R.; Wennberg, M.; Harlid, S.; Johansson, I.; Shivappa, N.; Hébert, J.R.; Van Guelpen, B.; Nilsson, L.M. The inflammatory potential of diet in determining cancer risk; A prospective investigation of two dietary pattern scores. PLoS ONE 2019, 14, e0214551. [CrossRef]

55. Kotemori, A.; Sawada, N.; Iwasaki, M.; Yamaji, T.; Shivappa, N.; Hébert, J.R. Association between dietary inflammatory index and high-sensitive C-reactive protein levels in cancer screening in Japanese. Rev. Épidémiol. Santé 2018, 66, 347. [CrossRef]

56. Shivappa, N.; Hébert, J.R.; Steck, S.E.; Safari, A.; Sedaghat, F.; Rashidkhani, B. Dietary Inflammatory Index and Odds of Colorectal Cancer in a Case-Control Study from Iran. Asian Pac. J. Cancer Prev. 2018, 19, 1999-2006. [PubMed]

57. Lee, S.; Lee, J.; Choi, I.J.; Kim, Y.W.; Ryu, K.W.; Kim, Y.I.; Kim, J. Dietary inflammatory index and the risk of gastric cancer in a Korean population. Oncotarget 2017, 8, 85452-85462. [CrossRef] [PubMed]

58. Cho, Y.A.; Lee, J.; Oh, J.H.; Shin, A.; Kim, J. Dietary Inflammatory Index and Risk of Colorectal Cancer: A Case-Control Study in Korea. Nutrients 2016, 8, 469. [CrossRef] [PubMed]

59. Chamekh, M.; Casimir, G. Editorial: Sexual Dimorphism of the Immune Inflammatory Response in Infectious and Non-infectious Diseases. Front. Immunol. 2019, 10, 107. [CrossRef] [PubMed]

60. Ngo, S.T.; Steyn, F.J.; McCombe, P.A. Gender differences in autoimmune disease. Front. Neuroendocrinol. 2014, 35, 347-369. [CrossRef] [PubMed]

61. Casimir, G.J.; Duchateau, J. Gender differences in inflammatory processes could explain poorer prognosis for males. J. Clin. Microbiol. 2011, 49, 478-479. [CrossRef] [PubMed]

62. Wegner, A.; Benson, S.; Rebernik, L.; Spreitzer, I.; Jäger, M.; Schedlowski, M.; Elsenbruch, S.; Engler, H. Sex differences in the pro-inflammatory cytokine response to endotoxin unfold in vivo but not ex vivo in healthy humans. Innate Immun. 2017, 23, 432-439. [CrossRef] 
63. Lesuis, N.; Befrits, R.; Nyberg, F.; van Vollenhoven, R.F. Gender and the treatment of immune-mediated chronic inflammatory diseases: Rheumatoid arthritis, inflammatory bowel disease and psoriasis: An observational study. BMC Med. 2012, 10, 82. [CrossRef]

64. Dorak, M.T.; Karpuzoglu, E. Gender differences in cancer susceptibility: An inadequately addressed issue. Front. Genet. 2012, 3, 268. [CrossRef]

65. Reuter, S.; Gupta, S.C.; Chaturvedi, M.M.; Aggarwal, B.B. Oxidative stress, inflammation, and cancer: How are they linked? Free Radic. Biol. Med. 2010, 49, 1603-1616. [CrossRef]

66. Coussens, L.M.; Werb, Z. Inflammation and cancer. Nature 2002, 420, 860-867. [CrossRef] [PubMed]

67. Arulselvan, P.; Fard, M.T.; Tan, W.S.; Gothai, S.; Fakurazi, S.; Norhaizan, M.E.; Kumar, S.S. Role of Antioxidants and Natural Products in Inflammation. Oxid. Med. Cell. Longev. 2016, 2016, 5276130. [CrossRef] [PubMed]

68. Federico, A.; Morgillo, F.; Tuccillo, C.; Ciardiello, F.; Loguercio, C. Chronic inflammation and oxidative stress in human carcinogenesis. Int. J. Cancer 2007, 21, 2381-2386. [CrossRef] [PubMed]

69. Lobo, V.; Patil, A.; Phatak, A.; Chandra, N. Free radicals, antioxidants and functional foods: Impact on human health. Pharmacogn. Rev. 2010, 4, 118-126. [CrossRef] [PubMed]

70. Griffiths, K.; Aggarwal, B.B.; Singh, R.B.; Buttar, H.S.; Wilson, D.; De Meester, F. Food Antioxidants and Their Anti-Inflammatory Properties: A Potential Role in Cardiovascular Diseases and Cancer Prevention. Diseases 2016, 4, 28. [CrossRef] [PubMed]

71. Kuntz, S.; Wenzel, U.; Daniel, H. Comparative analysis of the effects of flavonoids on proliferation, cytotoxicity, and apoptosis in human colon cancer cell lines. Eur. J. Nutr. 1999, 38, 133-142. [CrossRef]

72. Ashoori, M.; Saedisomeolia, A. Riboflavin (vitamin $\mathrm{B}_{2}$ ) and oxidative stress: A review. Br. J. Nutr. 2014, 111, 1985-1991. [CrossRef]

73. Gülçin, İ. $\mathrm{Fe}(3+)-\mathrm{Fe}(2+)$ transformation method: An important antioxidant assay. Methods Mol. Biol. 2015, 1208, 233-246.

74. Wang, J.; Tung, T.; Yin, W.; Huang, C.; Jen, H.; Wei, J.; Young, M. Effects of moderate alcohol consumption on inflammatory biomarkers. Acta Cardiol. 2008, 63, 65-72. [CrossRef]

75. Zakhari, S.; Hoek, J.B. Epidemiology of Moderate Alcohol Consumption and Breast Cancer: Association or Causation? Cancers 2018, 10, 349. [CrossRef]

76. Stote, K.S.; Tracy, R.P.; Taylor, P.R.; Baer, D.J. The effect of moderate alcohol consumption on biomarkers of inflammation and hemostatic factors in postmenopausal women. Eur. J. Clin. Nutr. 2016, 70, 470-474. [CrossRef] [PubMed]

77. Hébert, J.R.; Shivappa, N.; Wirth, M.D.; Hussey, J.R.; Hurley, T.G. Perspective: The Dietary Inflammatory Index (DII $\left.{ }^{\circledR}\right)$ : Lessons Learned, Improvements Made and Future Directions. Adv. Nutr. 2019, 10, 185-195. [CrossRef] [PubMed]

78. Kim, H.S.; Kwon, M.; Lee, H.Y.; Shivappa, N.; Hébert, J.R.; Sohn, C.; Na, W.; Kim, M.K. Higher Pro-Inflammatory Dietary Score is Associated with Higher Hyperuricemia Risk: Results from the Case-Controlled Korean Genome and Epidemiology Study_Cardiovascular Disease Association Study. Nutrients. 2019, 11, 1803. [CrossRef] [PubMed]

(C) 2019 by the authors. Licensee MDPI, Basel, Switzerland. This article is an open access article distributed under the terms and conditions of the Creative Commons Attribution (CC BY) license (http://creativecommons.org/licenses/by/4.0/). 